\title{
Generational "Structural Flexibility" in the United Arab Emirati Family: Lewis Coser's Functions of Social Conflict Revisited
}

\author{
Mohammed Abdel Karim Al Hourani
}

\begin{abstract}
This study examined, to what extent the structure of spousal relationship in United Arab Emirati' (UAE) family has been changed from rigidity to flexibility among a sample of 168 pairs of daughters and mothers $(\mathrm{N}=336)$. Three propositions were derived from Coser's theory "functions of social conflict" to measure the structural flexibility: releasing the antagonistic claims, interdependency and reproducing of consensual agreements. Findings revealed that daughters and mothers reported a low level of structural flexibility in terms of the three propositions, however, daughters reported more flexibility than their mothers. This result indicates that the rapid and comprehensive change of the infrastructures didn't lead to a parallel change in the nontangible elements of UAE culture which are highly rooted in a composition of social traditions and Islamic values.
\end{abstract}

Mohammed Al Hourani is an Associate Professor in the Sociology Department, University of Sharjah/UAE. His research interests focus on gender inequality, ethnicity, refugees, disability, civic culture and civil society. Recent publications include the "Lived Experiences of Emirati Women in the Combined Family", "Life Course of Drug Addiction in Jordan: Grounded Theory Approach", "Post Divorce Experiences in Jordan: Phenomenological Approach" and "Life Course Stages of Handicaps empowerment in UAE: Applying Perspectives of Stigma and Gender Differentiation." 
Al Hourani

\section{Introduction}

The main objective of this article is to explore the differences of "structural flexibility" between two generations (married daughters/mothers) in order to understand and explain how rapid and comprehensive change in the last two decades impacted the structure of the spousal relationship which is one of the most particularistic relationships in UAE society.

The frequency and intensity of interactions, particularly in long term marriage, are fertile ground for the emergence of marital conflicts (Kulik, Walfisch \& Liberman, 2016). Researchers have focused on the way couples deal with these conflicts (Cohan \& Bradbury, 1994) or what has been defined as "spousal conflict resolution strategies" (Kerig, 1996). Thus, they neglected the nature of social structure and its value orientations which govern all dynamics of marital life and determine how spouses tend to resolve their conflicts.

The current exploratory study utilized Lewis Coser's theory of "The Functions of Social Conflict" to measure changes of marital relationships in UAE and to what extent have moved from rigid traditional relational structure to flexible one across generations.

The data presented in this study are very important because we know very little about the marital relationships in the modern nation of the UAE. The data also are important because they represent the cultural gap between the material advances and the vested social arrangements of marital relationships which stemmed from traditions and Islamic values.

\section{Family Structure and Relationships in $U A E$}

The United Arab Emirates was formed in 1971 after obtaining independence from Great Britain. Since the emergence of the UAE as one state, oil production and exportation created a great wealth thereby the country witnessed massive development and comprehensive 
modernization in its infra-structure and has become one of the most rich and developed countries in the region. The leadership has made great contacts with experts from developed and undeveloped countries to build the country's infra-structure. UAE nowadays, hosts more than 10 million of immigrants who are all contributing in its economic development. It is the nation that has been extremely transformed from traditional modes of production (Bedouin-desert life of sheep and camels, farming, diving for pearls) to modern capital in nearly five decades (Alsayar, 1986)

Despite the rapid and profound changes of the material infrastructures, the superstructure didn't witness parallel changes, including the authoritative family structure and the relationships among family members. This means that the traditions of Emirati society are still dominating the family structure and relationships. That is to say, the Emirati family, traditionally, was the "extended family" in which several generations can be found under one roof. Such situations served as a productive-social unit which reflected functional necessity reproduced by the traditional mode of production where the hard existential conditions of living demanded high levels of solidarity, cooperation and joint action.

The Emirati extended family pattern was patriarchal and patrilineal based on age and sex (i.e. the authority and decision making in all aspects of family life were vested by males (father, husband and old sons) and women were obliged to subject and obey the orders.) Besides, women were less valued compared to males (Crabtree, 2007). This authoritarian hierarchy consecrated high levels of stability and equilibrium in the family structure. Although this hegemony stemmed from the material conditions of living, it has been associated with and masked by Islamic ideology by which the perfect woman should be submissive. Hence, the relationship between men and women excluded women from participating in decision making, negotiation, or expressions of emotional feelings. 


\section{Al Hourani}

Back in 1962, the oil produced for export and the changes in the infrastructures progressed gradually, including modern organizations, roads, schools, universities, hospitals, airports, ports and markets. This evolution, with the encouragement and support of the leadership (Sheikh Zayed), inspired the new generation of females to become involved in education; they entered school and continued their way forward in the college and university systems.

Due to the forces of modernization, the domestic work is no longer the goal of Emirati females and new skills needed for the market place. Nowadays, young women are representing the majority of students in Emirati universities, furthermore, they are representing (66\%) of the governmental force of work and (33\%) of the leading positions (Salom, 2012). Emirati women have become more independent, productive, participant, and decision makers in the governmental sector and in private properties of their own.

However, changes and openness in life chances, for women, didn't lead to profound changes in the very structure of the family. The superiority of males over females still exists due to the institutionalized Islamic beliefs and social traditions which reproduce gender differences and grant men the right to make decisions for the family.

Although the patriarchal structure of the family is still reproduced and maintained, the qualifications of women has raised their expectations toward public life and changed their point of view toward the traditionally patterned social regularities. For example, social inquiry on an Emirati family showed that the current generation of young Emirati women have different attitudes toward diverse subjects associated with family life such as preferring to delay the age of marriage, choosing their own spouses, asserting equal roles in regard to the assistance of men in rearing children, having a tendency to have fewer children and $93 \%$ of them have a 
deep desire to work out of the environment of domestic work (Schvaneveldt et. al. 2005).

Thus, educated and qualified Emirati women tend to be more participant, conscious and courageous enough to express their opinion and feelings, including their resentment and discontent. Consequently, the rising expectations of women about the spousal relationship created contradictions with the traditional patriarchal sub-culture. These contradictions led to dissatisfaction and deep awareness of deprivation for women besides, fissures, stresses and tensions in husband-wife relationship.

The problem of being overburdened faced young married women who were involved in the marketplace and spent much of time in their work. They couldn't communicate with family members as, traditionally, they did. Besides, they neglected their domestic obligations and children rearing (Foster et. al. 2014).

Consequently, a study conducted by Union Staff for Human Resources showed that the rising life chances for women affected family cohesion, and rates of divorce. For instance, out of 7,876 divorced women, $16 \%$ were divorced due to long working hours and less time for family (Abed, 2015).

Finally, high rates of divorce in UAE which estimated to be $35 \%$ (Joshan, 2015) indicates a structural problem in the institutions of marriage and family. That means that the family structure has not changed to release stress and tensions so that it is likely to further intensify the conflict once it breaks out.

\section{Theoretical Framework: Structural Flexibility}

In his theory, "the functions of social conflict", Coser distinguishes between two types of conflict; external conflict and internal conflict. Because this study investigates the structural flexibility, mainly, in the relationship between husband and wife in the Emirati family I have 


\section{Al Hourani}

to pay particular attention to the functions of internal conflict.

Coser argues that the closer the relationship and the more the participants are involved in it, the more occasions there are for conflict. The more frequent the interaction, the more occasions for hostile interaction (Coser, 1956:72).

In addition, Coser distinguishes between the conflict which concerns the very basis of a relationship and those which concern less central issues. So, within marriage a conflict on whether or not to have children involves the basic consensual agreement about the very purpose of the relationship. One may expect that this type of conflict will presumably have a more profound impact on the relationship than the conflict over particular plans to spend a vacation or to allocate the family budget (Coser, 1956:73-74).

Thus, internal conflict has the role of defining the group and maintaining its cohesion and stability if it is not about basic values and principles. This, in return, depends on the rigidity or on the structural flexibility of the social system, which emerging from frequent, low intensity and low violent conflicts, such conflicts come and go, thereby promoting a flexible structure (Turner, 1986: 174-175).

Structural flexibility, as Coser defined it, is the ability of a social system to allow occurrences of conflicts through which the expression and acting out of feelings leads to mutual and unilateral accommodation and adjustments between component parts. The channels for carrying out such conflicts would seem to constitute an important balancing mechanism in a social structure. This mechanism deals with conflicts through continuous readjustments so that the basic structure remains flexible enough to withstand internal strains. Consequently, in such flexible systems the danger of conflicts disturbing the basic consensus is minimized (Coser, 1956: 79). 
The current study is based on these assumptions which constitute structural flexibility and functionalize conflicts within the husband and wife relationship:

First assumption, releasing antagonistic claims; the fear of intense conflict may lead parties to suppress their hostile feelings. In return, the accumulation of such hostile feelings is likely to further intensify the conflict once it breaks out (Coser, 1956: 68). Hence, internal conflict serves as a safety valve, without which social hostility would eventually erupt violently. Coser suggests that when conflict emerges after having been suppressed for a long time, it will also split the group around basic issues and values (Wallace \& Wolf, 2006: 136).

Second, the interdependency; Coser argues that interdependency checks to some extent tendencies toward basic cleavages and exerts pressure against radical breaks away from the system (Coser, 1956: 75). The basic reason is that interdependency means that people with common interests in one respect are opposed in another, so that an overriding and polarizing issue is less likely (Wallace \& Wolf, 2006: 136).

Third, producing consensual agreements; Coser argues that the flexible systems make the danger of breakdowns and consensual agreements remote (Coser, 1956: 79). This is because internal conflict is central to defining a group's identity, which is embodied in norms that define correct behavior and this would lead to promoting flexible coordination which allows continuous readjustments within the system and increases capacity to innovate and create new rules for regulating conflict relations, besides, increasing awareness of realistic issues.

\section{Flexibility of the Husband-Wife Relationship}

The comparison of research literature on spousal relationships among Middle Eastern countries, and those which were conducted in the Western countries revealed that the structure of spousal relationships in Middle Eastern Countries is still rigid and based on traditional gender roles which give the right of authority and decision making to men even if women are 


\section{Al Hourani}

participating in public life, and making their own earnings (Hatog, 2001; Faten, 1986).

This contradiction between what the woman's status ought to be in relation with her husband and current dynamic socio-cultural change, promoted hostile confrontations, disagreements and conflicts between wives and husbands (Alkharoof \& Alqamash, 2005; Al Moaseb, 2017; Rayhan \& Diab, 1984). Most often, women who express their discontent and dissatisfaction and argue with their husbands expose themselves to various types of violence. For example, the rate of physical violence only in Emirati society is about $17 \%$ of women who submitted complaints against their husbands (Abu Naama, 2016). Initially, such a result supports the notion of structural rigidity in the spousal relationship, where freeing and releasing hostile feelings is suppressed. Furthermore, the traditionally institutionalized hierarchal structure of family prevents interdependency and an egalitarian relationship. Thereby, the creation of new rules for regulating new coming conflicts couldn't emerge through the differentiation of power between husband and wife.

In comparing an Arab Islamic family with an Israeli family structure, which is in the region, the Israeli family structure is flexible. Research findings revealed that integration was the most prevalent strategy used by both spouses, whereas dominance and avoidance is the least prevalent strategies. Comparisons revealed that husbands showed a greater tendency than their wives to adopt the strategies of compromise, concession and avoidance specifically in late adulthood. Moreover, integration contributed most significantly to explaining assessments of marital life (Kulik; Walfisch \& Liberman: 2016; Kulik \& Havusha, 2010).

On the other hand, research in the West supports, in general, the notion of structural flexibility which is based, as some results revealed, on marital dialogue as a central dimension of family integration and as a mechanism of overcoming conflicts and disagreement between 
spouses. Moreover, the more the spouses resolve their disputes by dialogue the more they love each other (Danijela, 2008). It seems that dialogue is more effective and beneficial in late adulthood than in early adulthood, because the spouses, over and over, experience the benefits of dialogue in protecting their family and avoid intense conflicts or divorce (Sybil \& Gottman, 2004). This means that the structural flexibility develop along with marital experience over time.

Feelings expression, interdependency, and open communication, not only helps spouses manage their stresses, but also helps them acquire marital stability and satisfaction (Waldinger et. al. 2004; Burke, Firth \& McGrattan, 1974).

Although some spouses follow the strategy of avoidance in order to resolve the conflict with spouses or to avoid spousal anger, research revealed that this strategy doesn't lead to a real resolution for conflict (Ball et. al. 2004; Chan, 1990). In return, research findings showed that the soft cooperative styles such as integration, compromise and concession institutionalize marital compatibility (Hanzel \& Segrin, 2009). Soft strategies affects, to a large extent, marital satisfaction. Thereby, how spouses think and behave to resolve conflict make a big difference in the marital relationship (Kurdik, 1995).

\section{Rationale for the Study}

Most of the existing knowledge about the dimensions of structural flexibility in family relations such as spousal conflict, husband-wife conflict resolution styles and stress management between spouses comes from studies conducted with U.S samples. Research on structural flexibility and its intergenerational changing status is greatly needed for the Emirates and for all the Gulf nations. The study of relational flexibility between spouses in the course of rapid socio-economic change didn't receive sociological attention, although the dynamic 
Al Hourani

change impacted a vast plausible changes in social structures. Since only a small body of research literature exists, all types of research dealing with family life and dynamics would be of great benefit.

The current study is especially important because of the need to better understand the change in the spousal relationship between two generations. Mothers of the respondents in this study were raised in the traditional context of the extended family which legitimized the suppression of women, and the priority and superiority for men in all aspects of life. In contrast, their daughters have grown up in a world of openness, education, opportunities in public work, and orientations of gender equality. In fact, the differences of the two contexts between mothers and daughters is dramatic. But, to what extent does spousal relationship move from rigidity to flexibility in the changing social context? This deserves sociological research attention.

\section{Method}

A self-administrated questionnaire was developed based on Coser's theory (The Functions of Social Conflict), to obtain information about the differences of structural stability in Emirati spouses' relationships as seen by young women at the University of Sharjah and the community of Sharjah Emirate and their mothers. Three dimensions of structural flexibility were derived from Coser's theory; releasing antagonistic claims, interdependency, and reproducing consensual agreements.

The data were collected in 2016-2017. The instrument was pre-tested on a pilot group of students and their mothers, and after needed revision, was used to collect data on 168 pairs of daughters and mothers for a total sample size of 336. A scale of four response categories (to a large degree, to a moderate degree, to a small degree, not at all) was employed to assess the degree of similarity and differences between daughters and their mothers in regard to their 
relational flexibility as it is embodied in the actual interactional experience with the spouse.

Most of daughters (105) were students at the University of Sharjah and they completed the questionnaire in a classroom setting and were provided with a copy of the questionnaire for their mothers to complete at home. The rest of the daughters (63) were friends or relatives of the female research assistant who are lived in the community of Sharjah, and the same procedures were followed with them and their mothers except they completed the instrument in their homes. Data were analyzed for descriptive statistics and t-test analyses were performed to illustrate the differences in responses between daughters and mothers.

It should be noted that the sample was selected from wives only. This is justified by the nature of the structure of Emirati family where the dynamics of spousal relationships are governed and controlled by men. Hence, the returns of the spousal relationship should be realized by the wife who is the subordinate party.

\section{Results}

Table 1

Socio-demographic Variables

\begin{tabular}{|c|r|c|c|c|c|}
\hline \multirow{4}{*}{ Variable } & \multirow{2}{*}{ Category } & \multicolumn{2}{|c|}{ Daughters (166) } & \multicolumn{2}{c|}{ Mothers (166) } \\
\cline { 3 - 6 } & & Freq. & Per\% & Freq. & Per\% \\
\hline \multirow{5}{*}{ Educational Attainment } & No Education & - & - & 118 & 71.1 \\
\cline { 2 - 7 } & Elementary & - & - & 12 & 7.2 \\
\cline { 2 - 7 } & Basic & - & - & 5 & 3.1 \\
\cline { 2 - 7 } & Secondary & - & - & 9 & 5.4 \\
\cline { 2 - 7 } & B.S. Degree & 159 & 95.7 & 19 & 11.4 \\
\cline { 2 - 6 } & Graduate S. & 7 & 4.3 & 3 & 1.8 \\
\hline
\end{tabular}


Al Hourani

\begin{tabular}{|c|r|c|c|c|c|}
\hline \multirow{3}{*}{$\begin{array}{c}\text { Education Attainment } \\
\text { for Husband }\end{array}$} & No Education & 11 & 6.6 & 93 & 56.1 \\
\cline { 2 - 6 } & Elementary & 15 & 9.1 & 11 & 6.6 \\
\cline { 2 - 6 } & Basic & 22 & 13.2 & 17 & 10.2 \\
\cline { 2 - 6 } & Secondary & 8 & 4.9 & 24 & 14.5 \\
\cline { 2 - 6 } & B.S. Degree & 101 & 60.8 & 19 & 11.4 \\
\cline { 2 - 6 } & Graduate S. & 9 & 5.4 & 2 & 1.2 \\
\cline { 2 - 6 } & Total & $\mathbf{1 6 6}$ & $\mathbf{1 0 0}$ & $\mathbf{1 6 6}$ & $\mathbf{1 0 0}$ \\
\hline
\end{tabular}

\begin{tabular}{|c|c|c|c|c|c|}
\hline \multirow{7}{*}{ Number of Children } & $1-2$ & 95 & 57.2 & 7 & 4.2 \\
\hline & $3-4$ & 60 & 36.2 & 24 & 14.5 \\
\hline & $5-6$ & - & & 57 & 34.3 \\
\hline & $7-8$ & - & & 44 & 26.5 \\
\hline & More than 8 & - & & 34 & 20.5 \\
\hline & Without & 11 & 6.6 & - & - \\
\hline & Total & 166 & 100 & 166 & 100 \\
\hline \multirow{7}{*}{ Place of Residence } & Sharjah & 94 & 56.7 & 101 & 60.8 \\
\hline & Dubai & 19 & 11.4 & 21 & 12.6 \\
\hline & Abu Dhabi & 10 & 6 & 7 & 4.3 \\
\hline & Ajman & 19 & 11.4 & 27 & 16.2 \\
\hline & $\begin{array}{l}\text { Ras Al } \\
\text { Khaymah }\end{array}$ & 9 & 5.4 & 3 & 1.8 \\
\hline & $\begin{array}{l}\text { Umm Al } \\
\text { Quwain }\end{array}$ & 8 & 4.8 & 7 & 4.3 \\
\hline & Fujairah & 7 & 4.3 & - & - \\
\hline
\end{tabular}


Generational "Structural" Flexibility in the United Arab Emirati Family

\begin{tabular}{|c|c|c|c|c|c|}
\hline & Total & 166 & 100 & 166 & 100 \\
\hline \multirow{5}{*}{ Family Income } & Less than 30 & & & & 4.3 \\
\hline & Thousands & 13 & 7.8 & 7 & \\
\hline & $30-50$ & 110 & 66.3 & 121 & 72.8 \\
\hline & More than 50 & 43 & 25.9 & 38 & 22.9 \\
\hline & Total & 166 & 100 & 166 & 100 \\
\hline \multirow[t]{3}{*}{ Are You Currently } & Yes & 23 & 13.8 & 8 & 4.8 \\
\hline & No & 143 & 86.2 & 158 & 95.2 \\
\hline & Total & 166 & 100 & 166 & 100 \\
\hline \multirow{3}{*}{$\begin{array}{l}\text { Is Your Husband } \\
\text { Currently Working? }\end{array}$} & Yes & 147 & 88.6 & 73 & 43.9 \\
\hline & No & 19 & 11.4 & 93 & 56.1 \\
\hline & Total & 166 & 100 & 166 & 100 \\
\hline \multirow{3}{*}{ Type of Marriage } & Traditional & 153 & 92.2 & 166 & 100 \\
\hline & Modern & 13 & 7.8 & - & - \\
\hline & Total & 336 & 100 & 166 & 100 \\
\hline \multirow[t]{3}{*}{ Is Your Husband From } & Yes & 113 & 68.1 & 141 & 84.9 \\
\hline & No & 53 & 31.9 & 25 & 15.1 \\
\hline & Total & 166 & 100 & 166 & 100 \\
\hline \multirow{6}{*}{$\begin{array}{l}\text { How Many Years the } \\
\text { Gap between You And }\end{array}$} & $1-5$ & 138 & 83.1 & 48 & 29 \\
\hline & $6-10$ & 11 & 6.6 & 62 & 37.3 \\
\hline & $11-15$ & 8 & 4.8 & 25 & 15.1 \\
\hline & $16-20$ & 7 & 4.3 & 18 & 10.8 \\
\hline & More than 21 & 2 & 1.2 & 13 & 7.8 \\
\hline & Total & 166 & 100 & 166 & 100 \\
\hline
\end{tabular}




\begin{tabular}{|c|c|c|c|c|c|}
\hline \multirow{4}{*}{ Duration of Marriage } & Less than 4 & 132 & 79.5 & - & - \\
\hline & $5-9$ & 29 & 17.4 & - & - \\
\hline & More than 9 & 5 & 3.1 & 166 & 100 \\
\hline & Total & 336 & 100 & & 100 \\
\hline \multirow{5}{*}{$\begin{array}{c}\text { What is Your Rank } \\
\text { Among Wives? }\end{array}$} & First only & 158 & 95.2 & 130 & 78.3 \\
\hline & Second & 8 & 4.8 & 20 & 12.1 \\
\hline & Third & - & - & 13 & 7.8 \\
\hline & Fourth & - & - & 3 & 1.8 \\
\hline & Total & 166 & 100 & 166 & 100 \\
\hline
\end{tabular}

Descriptive statistics (see Table 1 above) indicated that the vast majority of daughters (95.7\%) had higher education (B.S Degree). The vast majority of mothers $(71.1 \%)$ had no education. The daughters were already university students but higher education was less common among the older generations in UAE. The same result was indicated for husbands. The husbands of daughters have higher rates of education $(60.8 \%)$ B.S degree and graduate (5.4\%). Most of the fathers had no education $(56.1 \%)$ and few of them attained higher education (B.S degree $11.4 \%$, graduate (1.2\%). Furthermore, most of the daughters (57.2\%) had one or two children and $36.2 \%$ had three or four children. In return, $34.3 \%$ of the mothers had five to six children, $26.5 \%$ had from seven to eight children and $20.5 \%$ had more than eight children. The duration of marriage for the vast majority of daughters $(79.5 \%)$ was less than four years and all of mothers $(100 \%)$ were more than nine years. This result indicates that younger generation like to have greater control over reproduction and possibly want fewer children.

The majority of daughters (92.2\%) as well as all the mothers (100\%) reported that they 
were married traditionally (i.e. without a previous relationship with the partner), and most daughters $(68.1 \%)$ as well as the majority of mothers $(84.9 \%)$ reported that their husbands were relatives or from their kin group. This indicates that UAE society is still conservative and traditional in nature despite the considerable change in materials and infrastructures.

The majority of daughters $(83.1 \%)$ reported that the age gap between them and their husbands ranged from one to five years. In contrast, mothers reported that the gaps between them and their husbands was wider with a range six to ten years (37.3\%), a range of eleven to fifteen years (1\%), a range of sixteen to twenty years (10.8\%) and more than 21 years $(7.8 \%)$. This result indicates that the new generation of females were more likely than their mothers to report that they prefer a smaller age gap with their partners. This is because they claim that they have more freedom to agree or disagree on the personal characteristics of their partners. In contrast, the old generations of females didn't have the freedom to disagree, since decision were made by their fathers and family. The majority of daughters $(95.2 \%)$ and most mothers (78.3\%) claimed that they are the only wives, which indicates that monogamy is a new tendency in UAE.

Other differences were noted between generations in the daughters and mothers' responses in relation to structural flexibility in UAE families. Both mothers and daughters were asked to rate the degree of statements distributed on a three-dimensional scale of flexibility, with a range of responses of 4 to a large degree, 3 to a moderate degree, 2 to a small degree, 1 not at all. Results of t-tests are presented in Tables 2, 3 and 4. Significant difference were noted in the three dimensions of structural flexibility: expressing antagonistic claims, producing consensual agreements and interdependency. 
Al Hourani

Table 2

Expressing Antagonistic Claims

\begin{tabular}{|c|c|c|c|c|c|c|}
\hline \multirow[t]{2}{*}{ Items } & \multicolumn{2}{|c|}{ Mothers } & \multicolumn{2}{|c|}{ Daughters } & \multirow[b]{2}{*}{ T-value } & \multirow[b]{2}{*}{$\begin{array}{l}\text { signific } \\
\text { ance }\end{array}$} \\
\hline & SD & $\mathbf{M}$ & SD & $\mathbf{M}$ & & \\
\hline $\begin{array}{l}\text { It is not easy for me to } \\
\text { express all my true feelings to } \\
\text { my partner }\end{array}$ & 1.074 & $2.24 *$ & .960 & 2.00 & -2.143 & .033 \\
\hline $\begin{array}{l}\text { When we are having a } \\
\text { problem, my partner gives me } \\
\text { the silent treatment }\end{array}$ & 1.165 & $2.92 *$ & .994 & 2.63 & -2.417 & .016 \\
\hline $\begin{array}{l}\text { I am afraid to ask my partner } \\
\text { what I want }\end{array}$ & 1.242 & 3.66 & 1.343 & 3.42 & -1.687 & .092 \\
\hline $\begin{array}{l}\text { I wish my partner more } \\
\text { willing to share his feelings } \\
\text { with me }\end{array}$ & 1.194 & $1.92 *$ & .978 & 1.61 & -2.599 & .010 \\
\hline $\begin{array}{l}\text { My partner is not a good } \\
\text { listener for me }\end{array}$ & 1.167 & $2.23 *$ & .976 & 1.70 & -4.463 & .000 \\
\hline $\begin{array}{l}\text { I don't share my negative } \\
\text { feelings with my partner, } \\
\text { because I am afraid he will } \\
\text { get angry }\end{array}$ & 1.280 & 3.54 & 1.262 & 3.52 & -.086 & .932 \\
\hline $\begin{array}{l}\text { In order to end an argument, I } \\
\text { give up too quickly }\end{array}$ & 1.183 & 2.66 & 1.103 & 2.63 & -.239 & .812 \\
\hline
\end{tabular}


Generational "Structural" Flexibility in the United Arab Emirati Family

\begin{tabular}{|c|c|c|c|c|c|c|}
\hline $\begin{array}{l}\text { When my partner offends me } \\
\text { I suppress my discontent }\end{array}$ & 1.246 & $2.80 *$ & 1.088 & 2.54 & -2.006 & .046 \\
\hline $\begin{array}{l}\text { I often overcome my } \\
\text { dissatisfaction by courtesy }\end{array}$ & 1.242 & 3.38 & 1.105 & 3.39 & .093 & .926 \\
\hline $\begin{array}{l}\text { When I have a problem I } \\
\text { always tell my partner what is } \\
\text { bothering me }\end{array}$ & 1.207 & 2.15 & 1.018 & 1.98 & -1.368 & .172 \\
\hline $\begin{array}{l}\text { I express my feelings with } \\
\text { people than with my partner }\end{array}$ & 1.302 & 3.33 & 1.251 & 3.10 & -1.624 & .105 \\
\hline $\begin{array}{l}\text { In our relationship it is not } \\
\text { easy for both of us to express } \\
\text { our opinions }\end{array}$ & 1.117 & 2.26 & 1.000 & 2.02 & -2.110 & .036 \\
\hline $\begin{array}{l}\text { I and my partner can resolve } \\
\text { our disputes easily }\end{array}$ & 1.123 & 2.32 & 1.112 & 2.32 & .000 & 1.000 \\
\hline $\begin{array}{l}\text { Expressing antagonistic } \\
\text { claims }\end{array}$ & .411 & $2.72 *$ & .514 & 2.53 & -3.813 & .000 \\
\hline
\end{tabular}

$* \mathrm{p}<.05$

Both daughters and mothers reported a low ability to express their antagonistic feelings.

Yet, daughters reported more structural flexibility regarding the ability to express their antagonistic feelings with their husbands when compared with mothers, which indicates that structural rigidity in spousal relationship is still maintained along with the two generations. Mothers, as compared to daughters, stated that: it was not easy for me to express all my true 


\section{Al Hourani}

feelings to my partner, and that when we are having a problem, my partner gives me the silent treatment. Furthermore, the mothers wished their partners were more willing to share their feelings with them, and that their partners were not good listeners. Also, when the partner offends her, she suppresses her discontent.

Table 3

\section{Producing Consensual Agreements}

\begin{tabular}{|c|c|c|c|c|c|c|}
\hline \multirow[b]{2}{*}{ Items } & \multicolumn{2}{|c|}{ Mothers } & \multicolumn{2}{|c|}{ Daughters } & \multirow{2}{*}{$\begin{array}{l}\text { T- } \\
\text { value }\end{array}$} & \multirow{2}{*}{ Significance } \\
\hline & S.D & $\mathbf{M}$ & S.D & $\mathbf{M}$ & & \\
\hline $\begin{array}{l}\text { We are sharing the major } \\
\text { discisions of our family }\end{array}$ & 1.129 & 1.76 & .871 & 1.58 & -1.568 & .118 \\
\hline $\begin{array}{l}\text { We shift the household } \\
\text { responsibilities between us }\end{array}$ & 1.131 & 1.91 & .937 & 1.76 & -1.313 & .190 \\
\hline $\begin{array}{l}\text { We aren't flexible in how we } \\
\text { handle differences }\end{array}$ & 1.219 & $2.11 *$ & .952 & 1.75 & -2.993 & .003 \\
\hline $\begin{array}{l}\text { We have always solutions for our } \\
\text { problems }\end{array}$ & 1.044 & 2.39 & .974 & 2.24 & -1.351 & .178 \\
\hline $\begin{array}{l}\text { We don't have channels to } \\
\text { discuss our problems }\end{array}$ & 1.184 & $2.40 *$ & .968 & 2.10 & -2.572 & .011 \\
\hline $\begin{array}{l}\text { When problem arise we cannot } \\
\text { compromise easily }\end{array}$ & 1.244 & $2.60 *$ & 1.108 & 2.22 & -2.965 & .003 \\
\hline $\begin{array}{l}\text { My partner doesn't care for my } \\
\text { discussions about solving } \\
\text { problems }\end{array}$ & 1.344 & 3.72 & 1.397 & 3.72 & .000 & 1.000 \\
\hline
\end{tabular}


Generational "Structural" Flexibility in the United Arab Emirati Family

\begin{tabular}{|c|c|c|c|c|c|c|}
\hline $\begin{array}{l}\text { We try new ways of dealing with } \\
\text { problems and feel satisfied }\end{array}$ & 1.036 & 2.13 & .976 & 2.02 & -1.030 & .304 \\
\hline $\begin{array}{l}\text { When problem arise, we don't } \\
\text { think positively and quickly to } \\
\text { make an agreement }\end{array}$ & 1.204 & $2.48 *$ & 1.089 & 2.15 & -2.567 & .011 \\
\hline $\begin{array}{l}\text { We share interests and hobbies } \\
\text { with each other }\end{array}$ & 1.143 & 2.49 & 1.111 & 2.40 & -.774 & .439 \\
\hline $\begin{array}{l}\text { We have difficulty thinking of } \\
\text { things to do together }\end{array}$ & 1.186 & 2.42 & 1.102 & 2.16 & -2.050 & .041 \\
\hline $\begin{array}{l}\text { My partner respects our } \\
\text { agreements }\end{array}$ & 1.205 & 2.05 & 1.007 & 1.83 & -1.818 & .070 \\
\hline $\begin{array}{l}\text { Dispute doesn't repeated on the } \\
\text { same reason once more }\end{array}$ & 1.191 & $2.92 *$ & 1.054 & 2.45 & -3.784 & .000 \\
\hline $\begin{array}{l}\text { Producing Consensual } \\
\text { Agreements }\end{array}$ & .736 & $2.41 *$ & .662 & 2.18 & -3.085 & .002 \\
\hline
\end{tabular}

$* p<.05$

Other differences were noted in producing consensual agreements. Mothers as compared to daughters, were more likely to report that they couldn't produce consensual agreements with their husbands as their daughters do. However, both of them reported a low ability to produce shared rules of behaviour. Mothers were more likely to report that they were not flexible with their partners when handling differences, and they didn't have the proper channels to discuss problems with them. Furthermore, when problems arose wives/husbands cannot compromise easily and they don't think positively and quickly to make an agreement. 
These results indicate that husbands tend to treat their wives on the basis of patriarchal authority which compels women to be obliged to obey and become submissive to their husbands.

\section{Table 4}

\section{Interdependency}

\begin{tabular}{|c|c|c|c|c|c|c|}
\hline \multirow[t]{2}{*}{ Items } & \multicolumn{2}{|c|}{ Mothers } & \multicolumn{2}{|c|}{ Daughters } & \multirow[t]{2}{*}{ T-value } & \multirow[t]{2}{*}{$\begin{array}{l}\text { signifi } \\
\text { cance }\end{array}$} \\
\hline & S.D & $\mathbf{M}$ & S.D & $\mathbf{M}$ & & \\
\hline $\begin{array}{l}\text { We have fair distribution of duties in our } \\
\text { family }\end{array}$ & 1.307 & $2.43 *$ & 1.059 & 1.93 & -3.899 & .000 \\
\hline $\begin{array}{l}\text { We depend on each other in making } \\
\text { family duties }\end{array}$ & 1.258 & $2.32 *$ & .975 & 1.89 & -3.490 & .001 \\
\hline $\begin{array}{l}\text { My partner seems disinterested in doing } \\
\text { his duties }\end{array}$ & 1.364 & 3.76 & 1.421 & 3.87 & .705 & .481 \\
\hline $\begin{array}{l}\text { My partner doesn't share me } \\
\text { responsibilities of family }\end{array}$ & 1.248 & 3.31 & 1.314 & 3.40 & .681 & .496 \\
\hline $\begin{array}{l}\text { My partner doesn't give me as I give to } \\
\text { him in family life }\end{array}$ & 1.411 & 3.36 & 1.472 & 3.51 & .946 & .345 \\
\hline $\begin{array}{l}\text { I and my partner tend to do more things } \\
\text { separately }\end{array}$ & 1.306 & 3.16 & 1.281 & 3.35 & 1.308 & .192 \\
\hline $\begin{array}{l}\text { In our marriage we share efforts to } \\
\text { overcome difficulties }\end{array}$ & 1.230 & $1.96 *$ & .895 & 1.52 & -3.702 & .000 \\
\hline
\end{tabular}


Generational "Structural" Flexibility in the United Arab Emirati Family

\begin{tabular}{|c|c|c|c|c|c|c|}
\hline $\begin{array}{l}\text { I couldn't achieve what I want without } \\
\text { my partner }\end{array}$ & 1.285 & $2.23 *$ & .953 & 1.66 & -4.629 & .000 \\
\hline $\begin{array}{l}\text { We spend much of time with each other } \\
\text { at home }\end{array}$ & 1.315 & $2.36 *$ & 1.025 & 2.05 & -2.406 & .017 \\
\hline $\begin{array}{l}\text { We consult each other on our personal } \\
\text { interests }\end{array}$ & 1.173 & $2.19 *$ & 1.026 & 1.91 & -2.327 & .021 \\
\hline $\begin{array}{l}\text { My partner pay less attention in our } \\
\text { marriage than I expect }\end{array}$ & 1.319 & 3.26 & 1.409 & 3.12 & -.959 & .338 \\
\hline $\begin{array}{l}\text { I feel satisfied regard sharing major } \\
\text { family issues with my partner }\end{array}$ & 1.171 & 1.98 & 1.048 & 1.77 & -1.718 & .087 \\
\hline $\begin{array}{l}\text { We depend on each other in all aspects of } \\
\text { our marriage }\end{array}$ & 1.228 & $2.09 *$ & 1.045 & 1.76 & -2.632 & .009 \\
\hline Interdependency & .439 & $2.65 *$ & .541 & 2.44 & -3.826 & .000 \\
\hline
\end{tabular}

$* \mathrm{p}<.05$

Both mothers and daughters reported a low level of interdependency with their husbands. Although, mothers compared to daughters, were more likely to report that they have a lower level of interdependency with their husbands. Mothers responded negatively to the statement that they have a fair distribution of duties in their families. The same response was reported to the statement that they and their husbands depend on each other in undertaking family duties. Furthermore, mothers reported more negative responses, in comparison with their daughters, toward the statement that they share efforts with their husbands to overcome difficulties, and they expressed the same responses to the statement that they couldn't achieve 
what they want without their partners. In comparison, mothers were more likely to report a low level of mutual consultation, dependency and spending time with their husbands than daughters.

This result explains that men, because they feel that they are in a superior status, tend to contempt the contributions of women, even if these contributions were important for them. Hence, men feel shameful to consult their wives, or to depend on them or even to spend time with them.

\section{Discussion}

The current study attempted to explain the extent to which the relationship between young wives and husbands is becoming more flexible as compared with the relationship of their parents. The rationale of this comparison is that the young wives and husbands have lived rapid and profound transformations in all aspects of social and material life. For example, they have high levels of education, income, luxury, freedom and cultural openness which is not found in the environment of the older generations.

The concept of structural flexibility is derived from Lewis Coser's functions of social conflict. Three dimensions of the concept were derived and applied to measure the flexibility in spousal relationships: expressing antagonistic feelings, producing consensual agreements, and interdependency.

The results showed that both daughters and mothers reported low levels of structural flexibility with their husbands. However, mothers were more likely to report less structural flexibility. These results illustrate that the UAE family is still reproducing its hierarchal structure and patriarchal authority across generations, Women are submissive so they couldn't interact with their husbands on the base of fairness and equality (Hatog, 2001; Faten, 1986). 
On the other hand, women represent an element of structural rigidity by transmitting the structure of subordination to their daughters. This vicious circle of socialization and reproduction of traditional structures prevents the real change in spousal relationships to come out. Daughters reported more structural flexibility than their mothers which meant that the forces of openness and modernity led to some détente in the position of women in society and especially in the family.

This détente, to some extent, provoked family disputes, conflicts and violence against women (Alkharoof \& Alqamash, 2005; Hind, 2017, Rayhan \& Dyab, 1984). Women have become more educated, independent, free and aware of their conditions which has raised their expectations and given them more ability to debate, and to confront their husbands.

This result, is somewhat consistent with Coser's argument that rigidity of social structure would lead to divisive social conflict (Coser, 1956:45). But, most often conflict doesn't emerge violently and divisively although there was a high level of rigidity for a long time due to religious and tribal ideology and kinship relationships which preserved spousal relationships from being collapsed. This ideology, which is working actively in UAE, has prevented women's hostility from emerging by converting oppressions to rights, thereby creating a "smooth subordination" by which women, willingly, tend to obey their husbands' orders and follow their decisions. But, this type of structure, which consecrates coercive marital compatibility (Hanzel \& Segrin, 2009) can never enable spouses to manage their stresses and acquire real marital satisfaction (Waldinger et al, 2004; Burke, Firth \& McGrattan, 1974).

This study has certain limitations as do all studies focusing on spousal relationships. For example, the sample doesn't represent all Emirates equally, and, of course, it is not possible to generalize these findings to the entire nation of the UAE. Despite that, the data is very 


\section{Al Hourani}

important for illustrating how family culture resists social change and reproduces itself in UAE despite the profound change in material life. This mismatch of the present changes and the rigid traditions, illustrates, for women, that material life only, doesn't create happy marriages, but the freedom in the frame of egalitarian structures is very important too. Thus, the implications and utility from these data are profound in terms of understanding the necessary conditions of flexibility for women's self-actualization, happiness of family, and fortified spousal relationships. Furthermore, these findings are very important for policy making in terms of understanding that ascension of society and improving quality of life should be starting from flexibilizing family relationships. 


\section{References}

Abed, A. (2015). “Twelve Thousand Divorces Through Three Years”. Emirate Today. 13 June.

Abu Naama, H. (2016). “17\% Wives Who Were Submitted Complaints Against Violent Husbands in Dubai”. Emirati Today. 11. Nov.

Al- Klharouf, A. \& Alqamash, F. (2005). "Educational Level of Woman and Decision Making in the Family: A Field Study in Sanaa”. Dirassat. 32(2), 23-44.

Al Moaseb, H. (2017). "Spousal Disputes Development in Kuwait". Journal of Gulf \& Al Jazeera. 43(165), 112-127.

Al Sayar, A. (1986). "Family and Social Change in Emirate". Social Affairs. 3(9), 3-16.

Ball, J. et al. (2004). "Who's Got the Power? Gender Differences in Partners Perceptions of Influence during Marital Problem-Solving Discussions." Family Process Institute. 34(3), 303321.

Burke, R., Firth, J \& McGrattan, Ch. (1974). "Husband-Wife Compatibility and the Management of Stress". The Journal of Social Psychology, 94, 243-252.

Chan, D. (1990). "Confrontation Behaviors, Perceived Understanding and Relationship Growth.” In D. Chan (ed.) Intimates in Conflict. Hillsdale, NJ: Erlbaum. 65-135.

Cohan, C. L. \& Bradbury, T. N. (1994). "Assessing Responses to Recurring Problems in Marriage. Evaluation of Marital Coping Inventory." Psychological Assessment, 6, 191-200.

Coser, L. (1956). The Functions of Social Conflict. New York: The Free Press.

Crabetree, S. (2007). "Culture, Gender and the Influence of Social Change amongst Emirate Families in the United Arab Emirates”. Journal of Comparative Family Studies, 38(4), 576587.

Danijela, M. (2008). "Marital Dialogue in Natural Family Planning”. Portal of Scientific Journal of Croatia. Renewed Life, 63(4), 438-502.

Foster, N.; Ibrahim, A. \& Ibrahim. (2014). “An Exploratory Study of Work-Life Balance and Work Family Conflicts in the United Arab Emirates." Skyline Business Journal, (IX) 1, 3442 .

Hanzel, A. \& Segrin, C. (2009). "The Role of Conflict Resolution Styles in Mediating the Relationship between Enduring Vulnerabilities and Marital Quality". Journal of Family Communication, 9, 150-169.

Hatog, D. (2001). Circassia's Wife Decision Making in Family. Unpublished M.A Thesis. Univ. of Jordan.

Jeries, F. (1986). Factors Affecting the Leadership of Woman in Jordan. Unpublished M.A. Thesis. Yarmouk University. Jordan.

Joshan, R. (2016). "34\% the Divorce Ratio in Emirate in 2015”. The Gulf. 16 June. 


\section{Al Hourani}

Kerig, P. K. (1996). "Assessing the Links between Interparental Conflict and Child Adjustment: The Conflicts and Problem Solving Scales". Journal of Family Psychology, 10, 454-473.

Kulik, L. \& Havusha-Morgensternm H. (2010). “An Ecological Approach to Explain Women's Adjustment in the Initial Stage of Marriage”. Contemporary Family Therapy, 75, 153-164.

Kulik, L. \& Walfisch, Sh. \& Liberman, G. (2016). "Spousal Conflict Resolution Strategies and Marital Relations in Late Adulthood". Personal Relationships, 23, 456-474.

Kurdik, L. (1995). "Predicting Change in Marital Satisfaction from Husbands and Wives Conflict Resolution Styles". Journal of Marriage and the Family, 57, 153-104.

Rayhan, J. \& Diab, H. (2016). "Analyzing the Mechanisms of Social Control in the Rural Family of Bab Al wadi Governance-Egypt". Journal of Agriculture, Economics \& Social Sciences, 7(10), 62-87.

Salom, R. (2012). "Emirate Woman Represents (66\%) of Labour Force and (33\%) in the Leading Positions." Emirate Today. 6 May.

Schvaneveldt, P.; Kerpelman, J. \& Schvaneveldt, J. (2005). "Generational and Cultural Changes if Family life in the United Arab Emirates: A Comparison of Mothers and Daughters". Journal of Comparative Family Studies, 36(1), 77-91.

Sybil, C. \& Gottman, J. (2004). "Predicting Divorce among Newlyweds From the First Three Minutes of Marital Conflict Discussion.” Family Process Institute, 38(3), 293-301.

Turner, J. (1986). The Structure of Sociological Theory. $4^{\text {th }}$ Ed. Homewood, Illinois: The Dorsey Press.

Waldinger, R. et al. (2004). "Reading Others Emotions, the Role of Intuitive Judgments in Predicting Marital Satisfaction Quality and Stability". Journal of Family Psychology, 18(1), 58-71.

Wallace, R. A. \& Wolf, A. (2006). Contemporary Sociological Theory: Expanding the Classical Tradition. $6^{\text {th }}$ ed. Upper Saddle River, New Jersey: Pearson Prentice Hall. 